nephron

Experimental

Nephrology

and Genetics
Nephron 2019;143:274-281

DOI: $10.1159 / 000502907$
Received: April 1, 2019

Accepted after revision: August 9, 2019

Published online: October 15, 2019

\title{
Early Biomarkers of Fabry Nephropathy: A Review of the Literature
}

\author{
Eleonora Riccio ${ }^{a}$ Massimo Sabbatini $^{b}$ Ivana Capuano ${ }^{b}$ Antonio Pisani ${ }^{b}$ \\ ${ }^{a}$ Department of Nephrology, Second University of Naples, Naples, Italy; ${ }^{b}$ Chair of Nephrology, Department of Public \\ Health, University Federico II of Naples, Naples, Italy
}

\section{Keywords}

Fabry nephropathy · Biomarkers · Early marker · Early diagnosis

\begin{abstract}
Progressive nephropathy is one of the main features of Fabry disease. Although some clinical signs of Fabry nephropathy are already present in childhood, patients are often diagnosed relatively late in the course of the disease due to the absence of specific clinical markers, while a timely diagnosis and the prompt start of enzyme replacement therapy may be beneficial in stabilizing renal function or slowing its decline. Proteinuria/albuminuria has been accepted as the most important marker for Fabry nephropathy; however, a large proportion of renal impairment occurs in nonalbuminuric state. Therefore, early biomarkers may be useful for early identification of kidney involvement. The aim of this article is to review the current available literature on all biomarkers of Fabry nephropathy, with a comprehensive and critical description of their utilization in early recognition of renal damage.

(c) 2019 S. Karger AG, Basel
\end{abstract}

\section{Introduction}

Fabry disease (FD) is an X-linked disorder caused by lysosomal $\alpha$-galactosidase A ( $\alpha$ Gal-A) deficiency, with subsequent deposition of undegraded glycosphingolipid

\section{KARGER}

(c) 2019 S. Karger AG, Basel

E-Mail karger@karger.com

www.karger.com/nef products, mainly globotriaosylceramide (Gb3), in multiple organs, that, together with other pathophysiological triggers (such as cellular death, compromised energy metabolism, small vessel injury, and tissue ischemia) are responsible of significant morbidity and premature death [1].

Nephropathy is one of the main features of FD: kidney involvement follows $\mathrm{Gb} 3$ deposition in all types of renal cells and is characterized by a progressive disease that usually leads, in untreated patients with classical mutations, to end-stage renal disease from the third to the fifth decade of life [2-5].

Although some clinical signs of Fabry nephropathy are already present in childhood, its heterogeneous and nonspecific presentation is associated with a delay in diagnosis of approximately 15 years, also due to the absence of specific clinical markers [6].

The availability of a disease-specific treatment with enzyme replacement therapy (ERT) and chaperone therapy, and the evidence that a severe renal dysfunction may compromise its effectiveness, stress the need for a prompt recognition of the early markers of organ involvement $[5$, 7-9].

To date, albuminuria and reduction of glomerular filtration rate (GFR) are the only markers of renal dysfunction in FD and the most important predictors of renal disease progression in adult Fabry patients $[5,7,8]$. Even Canadian Guidelines for treatment of FD (October 2018) report, as major criteria to satisfy the start of ERT, besides the findings of high-risk pathology on renal biopsy in 
males, only the reduction of GFR or persisting proteinuria of $500 \mathrm{mg} /$ day $/ 1.73 \mathrm{~m}^{2}$ or greater [10]. Therefore, unfortunately, the treatment with ERT is commonly delayed until proteinuria or even overt organ involvement occurs, when the reversibility of renal damage is difficult to achieve, and the prognosis is poor $[8,11-13]$.

Based on the 2 assumptions that early kidney involvement is clinically silent and early treatment is more likely to prevent progressive kidney injury, alternative markers of kidney dysfunction are mandated. So, the identification of biomarkers correlated to the earliest pathological findings is paramount, as these biomarkers may become a noninvasive, diagnostic method of preclinical renal involvement by FD.

We performed a review of the literature with PubMed, US National Library of Medicine, Google Scholar, and Cochrane Library databases to describe the "state of the art" in the knowledge on biomarkers in Fabry nephropathy, with a comprehensive and critical description of their utilization in early recognition of renal damage.

\section{Urine Microscopy}

Targeted urinary microscopy has been widely described as a noninvasive, inexpensive, accessible, and rapid diagnostic technique, especially applicable where plas$\mathrm{ma}$ and/or leucocyte $\alpha \mathrm{Gal}-\mathrm{A}$ activity and genotyping are not affordable or available. Different reports suggest that urine microscopy may be a useful tool for the noninvasive diagnosis of FD and for the assessment of disease progression [14-31]; however, it presents some limitations because its diagnostic value is not well established in patients with attenuated phenotypes (mainly in females), most of the findings are not pathognomonic of FD, and its prognostic value needs further evidence.

Desnick et al. [14] and Nagao et al. [15] described the common variety of birefringent Maltese cross (MC) pattern (oval fat bodies) in the urine sediment of FD patients when viewed under a polarized microscope; Birch et al. [16] and later Branton et al. [3] further described characteristic internal lamellation and irregular surface protrusions of MC particles in FD. More recently, Selvarajah et al. [17] identified a specific morphological population of MC particles (MC 2), characterized by lamellated appearance with protrusions, likely due to Gb3, and resembled "mosquito coils," that probably represents fragmentation of shed nephronal epithelial cells containing lysosomal Gb3. The authors demonstrated that albuminuria correlated with quantitative particle excretion, and that MC 2 particles were highly specific (100\%) and sensitive (100\%) for FD.

The deficiency in aGal-A in FD leads to the progressive accumulation of $\mathrm{Gb} 3$, which is identical to the CD77 membrane antigen. The same authors showed that characteristic CD77/Gb3-positive cells (GL3 cell) detection in urine of Fabry patients is also highly sensitive (97\%) and specific (100\%). Like MC 2 particles, GL3 cells were seen even in patients without clinical nephropathy [17].

Mulberry cells are frequently observed in the urinary sediment and are strongly suggestive of renal FD [18]. Nakamichi et al. [19] reported mulberry cells as distal tubular epithelial cells, in which Gb3 has accumulated, but no proof about their origin is reported in the literature; they are similar to oval fat bodies, but can be distinguished by the difference in refractivity, size, and inner lamellar appearance [19]. Some reports have suggested that the detection of urinary mulberry cells may be a useful tool to identify incipient FD nephropathy [20, 21]; however, screening for urinary mulberry cells has several limitations. First, the incidence of these cells in renal FD patients is unknown; second, a diagnosis can depend on the experience of the technician or physician performing the exam.

Another important finding in FD patients is the urinary loss of podocytes, a phenomenon known as podocyturia. Podocytes, which are a major target cell in Fabry nephropathy, do not proliferate and therefore continue accumulating aGal substrates throughout their whole lifespan, with morphologic and functional alterations, which may occur before the clinical evidence of proteinuria $[22,23]$. In particular, despite the exact mechanisms of podocyte detachment and podocyturia in FD are not fully understood, some authors reported that they are likely caused by the accumulation of $\mathrm{Gb} 3$, which interacts with actin causing cell contraction, slit diaphragm widening, and the coupling with integrins [24-28]. Trimarchi et al. $[27,29]$ showed that Fabry patients displayed higher levels of podocyturia compared to the normal population, suggesting that podocyturia could be an ideal biomarker to assess early glomerular involvement in FD. Moreover, Fall et al. [30] found a direct association between podocyturia and proteinuria and an inverse association between podocyturia and eGFR in male Fabry patients, concluding that there are important correlations between podocyturia and severity of Fabry nephropathy. In contrast, the finding of the study by Selvarajah et al. [17], of a relatively low-grade podocyte excretion (54\%) in urine from Fabry patients, is consistent with a glomerular injury which is slowly progressive, but does not endorse the 
use of podocyturia as a diagnostic or monitoring tool in FD. However, different limitations in the use of podocyturia as early marker of Fabry nephropathy have been reported: the main is that the diverse techniques used to assess podocyturia (microscopy of stained cells, proteomics-based assays, or mRNA quantification) have not yet been standardized to the point that they may enter/be used in clinical practice. Moreover, the available methods are time-consuming, expensive, and laborious, and the best urinary podocyte-specific markers have not been established [27-29]. Finally, podocytes are frequently lost in clusters and erratic; therefore, their intermittent loss in the urine may oblige physician to perform serial analyses of repeated urine samples to correctly evaluate the case [31]. In addition, since glomerular podocyte loss is thought to be irreversible, amelioration or halting of podocyturia may be a reasonable indicator of treatment efficacy on renal damage. Some authors have shown that patients on ERT had lower podocyturia, suggesting that treatment may stabilize podocytes attachment and reduce their irreversible loss, and concluding that podocyturia may also be used during the follow-up of patients on ERT in order to assess the response to treatment $[27,30]$. Trimarchi et al. [27] reported higher podocyturia and lower proteinuria in untreated patients compared to patients on ERT, suggesting that clinically covert podocyturia may antedate proteinuria; moreover, individuals on ERT presented worse renal function, which may indicate that enzyme therapy is currently started at advanced stages of FD. In contrast, in other studies [17,30], authors did not find differences in podocyturia between treated and untreated patients; however, proper assessment of ERT effect on podocyturia would require longitudinal studies to be done in the future.

\section{Proteinuria}

Albuminuria/proteinuria is usually considered to be the current gold standard and a sensitive biomarker for the Fabry nephropathy $[4,32]$. In classically affected patients, it usually emerges in the second or third decade of life and contributes to the progression of the FD nephropathy; in fact, it is one of the most important indicator of renal disease progression in both treated and untreated patients [5, 33]. Nevertheless, significant histological changes may occur without pathological albuminuria/ proteinuria [23,34], thus its sensitivity to identify incipient FD nephropathy is questionable $[6,35]$. Moreover, some authors reported that proteinuria may not be overt in patients with advanced kidney disease, and not correlates with GFR decline [3, 4]: in particular, Ortiz et al. [4] showed that the prevalence of proteinuria and its magnitude increased with decreasing renal function in both sexes, but several patients with eGFR $<60 \mathrm{~mL} / \mathrm{min} / 1.73 \mathrm{~m}^{2}$ had proteinuria $<300 \mathrm{mg} / 24 \mathrm{~h}$.

\section{Hyperfiltration}

It is reported that glomerular hyperfiltration (HF) may represent an early feature of Fabry nephropathy [36-38]. In particular, a recent study reported, in a cohort of 87 patients with classical FD, a prevalence of $\mathrm{HF}$ (estimated GFR $>130 \mathrm{~mL} / \mathrm{min} / 1.73 \mathrm{~m}^{2}$ corrected for age) of $24 \%$, which increased to $50 \%$ when only young-adult patients (age $\leq 40$ years) were considered. Moreover, the authors showed a negative correlation between estimated GFR and age, and with proteinuria levels and the presence of cardiovascular and other manifestations of FD, suggesting that HF in Fabry patients could be related predominantly to a predisease state [39]. An important limitation of this study, however, is the use of an equationbased GFR that, although is the one which better correlates with true GFR, needs to be confirmed by a nuclear medicine technique. Therefore, the authors concluded that HF may be considered a relatively frequent feature in young Fabry patients, in comparison to other diseases classically related to an early HF status [40-42], and, once suspected on the basis of an elevated eGFR, must be confirmed with a nuclear medicine technique, since its recognition represents a relevant feature to start nephroprotective treatments in the very early stages of the disease [39].

In line with these evidences, the Canadian Guidelines for treatment of FD (September 2017) report, among the minor criteria to satisfy the start of ERT, the finding of HF $\left(\right.$ GFR $\left.>135 \mathrm{~mL} / \mathrm{min} / 1.73 \mathrm{~m}^{2}\right)$ in at least 2 measurements of GFR by nuclear medicine techniques [10].

\section{Cystatin-C}

To overcome the limitations of creatinine as a marker of GFR $[43,44]$ and the difficulties linked to the feasibility of nuclear medicine techniques (Cr51-EDTA, ioehxol, or iothalamate clearance) that are expensive, time consuming, cumbersome, and difficult to repeat on a serial basis, Cystatin- $\mathrm{C}$ has been proposed as a marker of early changes of renal function in Fabry nephropathy. 
Cystatin $\mathrm{C}$ is a small $(13 \mathrm{kDa})$ monoglycosylate protease inhibitor, which is produced at a constant rate, is freely filtered by the glomeruli, and is completely reabsorbed and catabolized by proximal tubules. Its serum concentration is very sensitive to changes in GFR in the early phases of renal function impairment [45]. Different studies have demonstrated that the Cystatin $\mathrm{C}$ concentration is a superior and more sensitive marker than serum creatinine to detect early renal involvement or small decreases in the glomerular filtration rate in FD patients of both genders [46, 47]. In particular, Feriozzi et al. [48] showed that the accuracy of Cystatin $\mathrm{C}$ in highlighting early changes in renal function is likely to be for several reasons: in particular, its serum levels do not depend on age, sex, and muscle mass, and creatinine has a tubular secretion that increases with the reduction of renal function $[49,50]$.

\section{Urinary Gb3 and Globotriaosylsphingosine}

Molecules such as Gb3, the main substrate of the enzyme aGal-A [51], and its deacylation product globotriaosylsphingosine (Lyso-Gb3), accumulate due to the enzymatic defect and have been extensively considered as a possible biomarker of FD [6]. Their urinary excretion has been identified as the gold standard with better sensitivity to identify FD patients than the plasma levels [52-54]. However, there was no apparent correlation between their values and renal involvement, so there is no evidence of their utilization in assessing renal prognosis [55]. Moreover, different studies showed the importance of serum lyso-Gb3 levels as markers of Fabry nephropathy in both genders [52, 56-58]; in particular, Nowak et al. [57] reported that lyso-Gb3 was a useful marker along with the leukocyte $\alpha \mathrm{Gal}$-A activity for the diagnosis of females with FD and may be useful to assess which heterozygotes should be considered for treatment, even though they have normal aGal-A activities; the same authors, showed, in a following paper, an important relation between lyso-Gb3 serum levels and disease severity, enzyme replacement response, metabolic phenotyping, and genotype severity in males [58].

\section{Tubular and Glomerular Proteins}

Abnormal urinary excretion of some proteins may indicate impairment in the glomerular and tubular functions. In $\mathrm{FD}$, changes in the excretion of the markers of glomeru-

Early Markers of Fabry Nephropathy lar protein leakage transferrin, type IV collagen, and IgG, as well as proximal tubule reabsorptive dysfunction uromodulin, a1-microglobulin, retinol-binding protein, $\mathrm{N}$-acetyl$\beta$-D-glucosaminidase, and $\beta$-2-microglobulin have been reported.

In a study by Aguiar et al. [35], aimed to identify biomarkers of incipient nephropathy in FD, the authors have reported that analyzed biomarkers of glomerular (transferrinandtypeIV collagen)andtubular( $\alpha 1$-microglobulin, $\mathrm{N}$-acetyl- $\beta$-glucosaminidase, and alanine aminopeptidase) dysfunction were increased even in Fabry patients without evidence of nephropathy. Moreover, the correlation with estimated GFR was even stronger for type IV collagen and $\mathrm{N}$-acetyl- $\beta$-glucosaminidase than for albuminuria, indicating that such biomarkers seem more accurate than albuminuria in the identification of the FD nephropathy [30].

Association of uromodulin changes with the degree of the storage process in FD, and its reversibility by ERT suggests that uromodulin excretion monitoring may be a useful marker, particularly of response to treatment: in fact, a study by Vylet'al et al. [59] showed that urinary excretion of uromodulin was reduced in untreated Fabry patients and normalized in all patients on ERT.

Prabakaran et al. [60] showed a significant increase in the excretion of tubular urine protein markers a1microglobulin and retinol-binding protein and of glomerular urine protein marker IgG in a population of $13 \mathrm{fe}$ males with FD, with a correlation between changes in their excretion and albuminuria; moreover, the authors reported a decrease in the excretion of these proteins with ERT.

\section{Bikunin}

A study by Lepedda et al. [61] showed that urine levels of bikunin, also known as urinary trypsin inhibitor, are significantly higher in Fabry patients with renal impairment than in controls. This finding suggests that the amount of this proteoglycan in urine could represent a biomarker of renal impairment in Fabry patients, useful in monitoring renal functionality also in those patients without overt renal damage. Moreover, the authors showed that the origin of higher urine bikunin levels may imply a direct kidney involvement, and the secondary activation, in response to glycosphingolipids storage, of biochemical pathways related to inflammation [61]. Nevertheless, the mechanisms by which urine levels are elevated in Fabry patients remain unclear and need further evaluation. 


\section{Proteomics}

The proteomics approach has been applied in FD to find biomarkers that might allow the measurement of the disease severity, the prognosis and the evaluation of the therapy effects, in addition to the possibility to give some insights on the pathophysiology of the disease [62-69]. A study by Matafora et al. [70] showed that the urinary proteome of FD patients is different from normal subjects and allowed the identification of several proteins with an altered expression (among them uromodulin, prostaglandin $\mathrm{H} 2 \mathrm{D}$-isomerase, and prosaposin) that are known to play a role in the processes that might be involved in the disease pathophysiology, as inflammation, immune response, and glycosphingolipid metabolism. In particular, unlike to that reported in literature, the authors found the upregulation of uromodulin in the urine of Fabry patients; usually, kidney disease results in a marked decrease in the synthesis of uromodulin, as well as in the accumulation of abnormal uromodulin in tubular cells, leading to tubular cell death [71]. However, all the patients of the study by Matafora et al. [70] showed almost normal values for both creatinine and GFR, and therefore uromodulin upregulation could be considered as a very early marker of kidney damage at the tubular level. These findings confirm the possible role of the urinary concentration of uromodulin as a valuable biomarker for the development of chronic kidney disease [72].

An important limitation of these studies is the small number of analyzed patients and a lack of follow-up data; therefore, further studies are needed to confirm these data.

\section{Parapelvic Cysts}

The presence of parapelvic cysts has been linked to FD and reported in the literature as a possible feature of its renal involvement [73-77]. A recent study showed that the prevalence of parapelvic cysts, observed during a routine ultrasonography study, is significantly higher in FD patients (29\%) compared with patients with kidney disease of similar age and level of renal function (1.1\%) and that such prevalence becomes even higher (43\%) when the specific ultrasonography was performed [11]. Moreover, the authors did not report any statistical associations between parapelvic cysts and demographic, clinical or laboratory data of their Fabry patients.

The pathogenesis of parapelvic cysts in FD is unknown, but a possible role of glycosphingolipids has been postulated. In fact, it has been demonstrated that intrare- nal levels of 2 glycosphingolipids, such as glucosylceramide and ganglioside, were significantly higher in 2 mouse knockout models of polycystic kidney disease and of nephronophthisis [78-80]. It has also been shown that the glucosylceramide synthase inhibitor Genz-123346 effectively inhibited the cystogenesis in these models orthologous to human polycystic kidney disease [81]. This evidence allows us to hypothesize an indirect role of $\mathrm{Gb} 3$ storage also in the pathogenesis of parapelvic cysts formation in FD, potentially associated with altered local metabolism or peculiar genetic regulatory processes.

These data suggest that although to date parapelvic cysts cannot be considered a pathognomonic sign of FD, their presence should alert both nephrologists and radiologists to consider the diagnosis of FD, especially in subjects with an unclear family history of renal disease and when other stigmata of the disease are evident.

\section{Conclusions}

Proteinuria/albuminuria has been considered as the most important marker for Fabry nephropathy; however, a large proportion of renal impairment occurs in nonalbuminuric state. It is important to implement different strategies for earlier detection of Fabry nephropathy, aiming to prevent the long-term devastating outcomes of renal loss in FD. In this review, we have reported that limitations of albuminuria as a sensitive marker of early renal dysfunction in FD may be overcome by the newly identified biomarkers. Some of them, in fact, are impaired also in normoalbuminuric patients and showed better correlation with eGFR than albuminuria. However, direct comparisons of these biomarkers with albuminuria are needed to confirm their superiority in early detection of Fabry nephropathy.

\section{Statement of Ethics}

This article does not contain any studies with human participants or animals performed by any of the authors.

\section{Disclosure Statement}

The authors declare that they have no conflict of interest.

\section{Informed Consent}

Not applicable. 


\section{References}

1 Desnick RJ, Ioannou Y, Eng CM. Fabry disease: $a$-galactosidase A deficiency. Scriver $\mathrm{CH}$, Beaudet AL, Sly WS, et al: The Metabolic and Molecular Basis of Inherited Disease. New York: Mc Graw Hill; 1995. pp. 2741-84.

2 Pisani A, Visciano B, Imbriaco M, Di Nuzzi A, Mancini A, Marchetiello C, et al. The kidney in Fabry's disease. Clin Genet. 2014 Oct; 86(4):301-9.

3 Branton MH, Schiffmann R, Sabnis SG, Murray GJ, Quirk JM, Altarescu G, et al. Natural history of Fabry renal disease: influence of alpha-galactosidase A activity and genetic mutations on clinical course. Medicine (Baltimore). 2002 Mar;81(2):122-38.

4 Ortiz A, Oliveira JP, Waldek S, Warnock DG, Cianciaruso B, Wanner C; Fabry Registry. Nephropathy in males and females with Fabry disease: cross-sectional description of patients before treatment with enzyme replacement therapy. Nephrol Dial Transplant. 2008 May;23(5):1600-7.

5 Schiffmann R, Warnock DG, Banikazemi M, Bultas J, Linthorst GE, Packman S, et al. Fabry disease: progression of nephropathy, and prevalence of cardiac and cerebrovascular events before enzyme replacement therapy. Nephrol Dial Transplant. 2009 Jul;24(7): 2102-11.

6 Beirão I, Cabrita A, Torres M, Silva F, Aguiar $\mathrm{P}$, Laranjeira $\mathrm{F}$, et al. Biomarkers and imaging findings of Anderson-Fabry disease - what we know now. Diseases. 2017 Jun;5(2):E15.

7 Rombach SM, Smid BE, Bouwman MG, Linthorst GE, Dijkgraaf MG, Hollak CE. Long term enzyme replacement therapy for Fabry disease: effectiveness on kidney, heart and brain. Orphanet J Rare Dis. 2013 Mar;8(1):47.

8 Pisani A, Visciano B, Roux GD, Sabbatini M, Porto C, Parenti G, et al. Enzyme replacement therapy in patients with Fabry disease: state of the art and review of the literature. Mol Genet Metab. 2012 Nov;107(3):267-75

9 Cox TM. Biomarkers in lysosomal storage diseases. In: Metha A, Beck M, Sunder-Plassmann G, editors. Fabry disease: Perspectives from 5 years of FOS. Oxford: Oxford PharmaGenesis; 2006.

10 Sirrs S, Bichet DG, Iwanochko M, et al. Canadian Fabry Disease Treatment Guidelines, 2018. https://www.garrod.ca/wp-conent/uploads/2019/04/Canadian-Fabry-TreatmentGuidelines-2018-final.pdf

11 Pisani A, Petruzzelli Annicchiarico L, Pellegrino A, Bruzzese D, Feriozzi S, Imbriaco M, et al. Parapelvic cysts, a distinguishing feature of renal Fabry disease. Nephrol Dial Transplant. 2018 Feb;33(2):318-23.

12 Biegstraaten M, Arngrímsson R, Barbey F, Boks L, Cecchi F, Deegan PB, et al. Recommendations for initiation and cessation of enzyme replacement therapy in patients with Fabry disease: the European Fabry Working Group consensus document. Orphanet J Rare Dis. 2015 Mar; 10(1):36.
13 Pisani A, Spinelli L, Visciano B, Capuano I, Sabbatini M, Riccio E, et al. Effects of switching from agalsidase Beta to agalsidase alfa in 10 patients with anderson-fabry disease. JIMD Rep. 2013;9:41-8.

14 Desnick RJ, Dawson G, Desnick SJ, Sweeley CC, Krivit W. Diagnosis of glycosphingolipidoses by urinary-sediment analysis. N Engl J Med. 1971 Apr;284(14):739-44.

15 Nagao S, Satoh N, Inaba S, Iijima S. Concentric lamellar spheres in urine from a female carrier of and patients with Fabry's diseasewith special reference to polarization and electron microscopic comparison with nephrotic syndrome. J Dermatol. 1985 Feb; 12(1):70-8.

16 Birch DF, Fairley KF, Becker GJ, et al. A Color Atlas of Urine Microscopy. London: Chapman \& Hall Medical; 1994. pp. 76-7938.

17 Selvarajah M, Nicholls K, Hewitson TD, Becker GJ. Targeted urine microscopy in Anderson-Fabry disease: a cheap, sensitive and specific diagnostic technique. Nephrol Dial Transplant. 2011 Oct;26(10):3195-202.

18 Pabico RC, Atancio BC, McKenna BA, Pamukcoglu T, Yodaiken R. Renal pathologic lesions and functional alterations in a man with Fabry's disease. Am J Med. 1973 Sep; 55(3):415-25

19 Nakamichi T, Miyazaki M, Nakayama K, Sato M, Akiu N, Sato T, et al. Fabry's disease discovered with chance urinary mulberry cells: a case report. CEN Case Rep. 2013 May;2(1): 49-52.

20 Chong PF, Nakamura K, Kira R. Mulberries in the urine: a tell-tale sign of Fabry disease. J Inherit Metab Dis. 2018 Jul;41(4):745-6.

21 Shimohata $H$, Maruyama $H$, Miyamoto Y, Takayasu M, Hirayama K, Kobayashi M. Urinary mulberry cells and mulberry bodies are useful tool to detect late-onset Fabry disease. CEN Case Rep. 2017 Nov;6(2):14851.

22 Trimarchi H, Canzonieri R, Muryan A, Schiel A, Araoz A, Forrester M, et al. Copious podocyturia without proteinuria and with normal renal function in a young adult with Fabry disease. Case Rep Nephrol. 2015;2015: 257628.

23 Tøndel C, Kanai T, Larsen KK, Ito S, Politei JM, Warnock DG, et al. Foot process effacement is an early marker of nephropathy in young classic Fabry patients without albuminuria. Nephron. 2015;129(1):16-21.

24 Vogelmann SU, Nelson WJ, Myers BD, Lemley KV. Urinary excretion of viable podocytes in health and renal disease. Am J Physiol Renal Physiol. 2003 Jul;285(1):F40-8.

25 Wharram BL, Goyal M, Wiggins JE, Sanden SK, Hussain S, Filipiak WE, et al. Podocyte depletion causes glomerulosclerosis: diphtheria toxin-induced podocyte depletion in rats expressing human diphtheria toxin receptor transgene. J Am Soc Nephrol. 2005 Oct; 16(10):2941-52.
26 Trimarchi H. The kidney in Fabry disease: more than mere sphingolipids overload. J Inborn Errors Metab Screen. 2016;4:1-5.

27 Trimarchi H, Canzonieri R, Schiel A, Politei J, Stern A, Andrews J, et al. Podocyturia is significantly elevated in untreated vs treated Fabry adult patients. J Nephrol. 2016 Dec; 29(6):791-7.

28 Sanchez-Niño MD, Perez-Gomez MV, Valiño-Rivas L, Torra R, Ortiz A. Podocyturia: why it may have added value in rare diseases. Clin Kidney J. 2018 Oct;12(1):49-52.

29 Trimarchi H, Canzonieri R, CostalesCollaguazo C, Politei J, Stern A, Paulero M, et al. Early decrease in the podocalyxin to synaptopodin ratio in urinary Fabry podocytes. Clin Kidney J. 2019 Feb;12(1): 53-60.

30 Fall B, Scott CR, Mauer M, Shankland S, Pippin J, Jefferson JA, et al. Urinary podocyte loss is increased in patients with Fabry disease and correlated with clinical severity of Fabry nephropathy. PLoS One. 2016 Dec;11(12): e0168346.

31 Trimarchi H. Podocyturia: potential applications and current limitations. World J Nephrol. 2017 Sep;6(5):221-8.

32 Ortiz A, Oliveira JP, Wanner C, Brenner BM, Waldek S, Warnock DG. Recommendations and guidelines for the diagnosis and treatment of Fabry nephropathy in adults. Nat Clin Pract Nephrol. 2008 Jun;4(6):32736.

33 Wanner C, Oliveira JP, Ortiz A, Mauer M, Germain DP, Linthorst GE, et al. Prognostic indicators of renal disease progression in adults with Fabry disease: natural history data from the Fabry Registry. Clin J Am Soc Nephrol. 2010 Dec;5(12):2220-8.

34 Tøndel C, Bostad L, Larsen KK, Hirth A, Vikse BE, Houge G, et al. Agalsidase benefits renal histology in young patients with Fabry disease. J Am Soc Nephrol. 2013 Jan;24(1): 137-48.

35 Aguiar P, Azevedo O, Pinto R, Marino J, Baker R, Cardoso C, et al. New biomarkers defining a novel early stage of Fabry nephropathy: A diagnostic test study. Mol Genet Metab. 2017 Jun;121(2):162-9.

36 West M, Nicholls K, Mehta A, Clarke JT, Steiner R, Beck M, et al. Agalsidase alfa and kidney dysfunction in Fabry disease. J Am Soc Nephrol. 2009 May;20(5):1132-9.

37 Rombach SM, Baas MC, ten Berge IJ, Krediet RT, Bemelman FJ, Hollak CE. The value of estimated GFR in comparison to measured GFR for the assessment of renal function in adult patients with Fabry disease. Nephrol Dial Transplant. 2010 Aug;25(8): 2549-56.

38 Vedder AC, Linthorst GE, van Breemen MJ, Groener JE, Bemelman FJ, Strijland A, et al. The Dutch Fabry cohort: diversity of clinical manifestations and Gb3 levels. J Inherit Metab Dis. 2007 Feb;30(1):68-78. 
39 Riccio E, Sabbatini M, Bruzzese D, Annicchiarico Petruzzelli L, Pellegrino A, Spinelli L, et al.; on behalf of AFFIINITY Group. Glomerular hyperfiltration: an early marker of nephropathy in Fabry disease. Nephron. 2019; 141(1):10-7.

40 Palatini P. Glomerular hyperfiltration: a marker of early renal damage in pre-diabetes and pre-hypertension. Nephrol Dial Transplant. 2012 May;27(5):1708-14.

41 Helal I, Reed B, McFann K, Yan XD, FickBrosnahan GM, Cadnapaphornchai $\mathrm{M}$, et al. Glomerular hyperfiltration and renal progression in children with autosomal dominant polycystic kidney disease. Clin J Am Soc Nephrol. 2011 Oct;6(10):2439-43.

42 Haymann JP, Stankovic K, Levy P, Avellino V, Tharaux PL, Letavernier E, et al. Glomerular hyperfiltration in adult sickle cell anemia: a frequent hemolysis associated feature. Clin J Am Soc Nephrol. 2010 May;5(5):75661.

43 Rule AD, Larson TS, Bergstralh EJ, Slezak JM, Jacobsen SJ, Cosio FG. Using serum creatinine to estimate glomerular filtration rate: accuracy in good health and in chronic kidney disease. Ann Intern Med. 2004 Dec;141(12): 929-37.

44 Agarwal R. Estimating GFR from serum creatinine concentration: pitfalls of GFR-estimating equations. Am J Kidney Dis. 2005 Mar;45(3):610-3.

45 Bicik Z, Bahcebasi T, Kulaksizoglu S, Yavuz $\mathrm{O}$. The efficacy of cystatin $\mathrm{C}$ assay in the prediction of glomerular filtration rate. Is it a more reliable marker for renal failure? Clin Chem Lab Med. 2005;43(8):855-61.

46 Torralba-Cabeza MA, Olivera S, Hughes DA, Pastores GM, Mateo RN, Pérez-Calvo JI. Cystatin $\mathrm{C}$ and NT-proBNP as prognostic biomarkers in Fabry disease. Mol Genet Metab. 2011 Nov; 104(3):301-7.

47 Perkins BA, Nelson RG, Ostrander BE, Blouch KL, Krolewski AS, Myers BD, et al. Detection of renal function decline in patients with diabetes and normal or elevated GFR by serial measurements of serum cystatin $\mathrm{C}$ concentration: results of a 4-year follow-up study. J Am Soc Nephrol. 2005 May; 16(5):1404-12.

48 Feriozzi S, Germain DP, Di Vito R, Legrand A, Ricci R, Barbey F. Cystatin C as a marker of early changes of renal function in Fabry nephropathy. J Nephrol. 2007 Jul-Aug;20(4): $437-43$.

49 Shemesh O, Golbetz H, Kriss JP, Myers BD. Limitations of creatinine as a filtration marker in glomerulopathic patients. Kidney Int. 1985 Nov;28(5):830-8.

50 Tenstad O, Roald AB, Grubb A, Aukland K. Renal handling of radiolabelled human cystatin C in the rat. Scand J Clin Lab Invest. 1996 Aug;56(5):409-14.

51 Sweeley CC, Klionsky B. Fabry's Disease: Classification as a Sphingolipidosis and Partial Characterization of a Novel Glycolipid. J Biol Chem. 1963 Sep;238:3148-50.
52 Young E, Mills K, Morris P, Vellodi A, Lee P, Waldek $\mathrm{S}$, et al. Is globotriaosylceramide a useful biomarker in Fabry disease? Acta Paediatr Suppl. 2005 Mar;94(447):51-4.

53 Auray-Blais C, Ntwari A, Clarke JT, Warnock DG, Oliveira JP, Young SP, et al. How well does urinary lyso-Gb3 function as a biomarker in Fabry disease? Clin Chim Acta. 2010 Dec;411(23-24):1906-14.

54 Auray-Blais C, Cyr D, Ntwari A, West ML, Cox-Brinkman J, Bichet DG, et al. Urinary globotriaosylceramide excretion correlates with the genotype in children and adults with Fabry disease. Mol Genet Metab. 2008 Mar; 93(3):331-40

55 Schiffmann R, Waldek S, Benigni A, AurayBlais C. Biomarkers of Fabry disease nephropathy. Clin J Am Soc Nephrol. 2010 Feb; 5(2):360-4.

56 Rombach SM, Dekker N, Bouwman MG, Linthorst GE, Zwinderman AH, Wijburg FA, et al. Plasma globotriaosylsphingosine: diagnostic value and relation to clinical manifestations of Fabry disease. Biochim Biophys Acta. 2010 Sep;1802(9):741-8.

57 Nowak A, Mechtler TP, Desnick RJ, Kasper DC. Plasma LysoGb3: A useful biomarker for the diagnosis and treatment of Fabry disease heterozygotes. Mol Genet Metab. 2017 Jan Feb;120(1-2):57-61.

58 Nowak A, Mechtler TP, Hornemann T, Gawinecka J, Theswet E, Hilz MJ, et al. Genotype, phenotype and disease severity reflected by serum LysoGb3 levels in patients with Fabry disease. Mol Genet Metab. 2018 Feb;123(2): $148-53$.

59 Vylet’al $\mathrm{P}$, Hůlková $\mathrm{H}$, Zivná $\mathrm{M}$, Berná L, Novák P, Elleder M, et al. Abnormal expression and processing of uromodulin in Fabry disease reflects tubular cell storage alteration and is reversible by enzyme replacement therapy. J Inherit Metab Dis. 2008 Aug;31(4):508-17.

60 Prabakaran T, Birn H, Bibby BM, Regeniter A, Sørensen SS, Feldt-Rasmussen U, et al. Long-term enzyme replacement therapy is associated with reduced proteinuria and preserved proximal tubular function in women with Fabry disease. Nephrol Dial Transplant. 2014 Mar;29(3):619-25.

61 Lepedda AJ, Fancellu L, Zinellu E, De Muro P, Nieddu G, Deiana GA, et al. Urine bikunin as a marker of renal impairment in Fabry's disease. BioMed Res Int. 2013;2013:205948.

62 Cigna D, D’Anna C, Zizzo C, Francofonte D, Sorrentino I, Colomba P, et al. Alteration of proteomic profiles in PBMC isolated from patients with Fabry disease: preliminary findings. Mol Biosyst. 2013 Jun;9(6):1162-8.

63 Vojtová L, Zima T, Tesař V, Michalová J, Přikryl P, Dostálová G, et al. Study of urinary proteomes in Anderson-Fabry disease. Ren Fail. 2010;32(10):1202-9.

64 Manwaring V, Heywood WE, Clayton R, Lachmann RH, Keutzer J, Hindmarsh P, et al. The identification of new biomarkers for identifying and monitoring kidney disease and their translation into a rapid mass spec- trometry-based test: evidence of presymptomatic kidney disease in pediatric Fabry and type-I diabetic patients. J Proteome Res. 2013 May;12(5):2013-21.

65 Hollander Z, Dai DL, Putko BN, Yogasundaram $\mathrm{H}$, Wilson-McManus JE, Thompson RB, et al. Gender-specific plasma proteomic biomarkers in patients with Anderson-Fabry disease. Eur J Heart Fail. 2015 Mar;17(3):291300.

66 Weidemann F, Breunig F, Beer M, Sandstede J, Störk S, Voelker W, et al. The variation of morphological and functional cardiac manifestation in Fabry disease: potential implications for the time course of the disease. Eur Heart J. 2005 Jun;26(12):1221-7.

67 Niemann M, Herrmann S, Hu K, Breunig F, Strotmann J, Beer M, et al. Differences in Fabry cardiomyopathy between female and male patients: consequences for diagnostic assessment. JACC Cardiovasc Imaging. 2011 Jun; 4(6):592-601.

68 MacDermot KD, Holmes A, Miners AH. Anderson-Fabry disease: clinical manifestations and impact of disease in a cohort of 60 obligate carrier females. J Med Genet. 2001 Nov; 38(11):769-75.

69 Feldt-Rasmussen U, Dobrovolny R, Nazarenko I, Ballegaard M, Hasholt L, Rasmussen AK, et al. Diagnostic dilemma: a young woman with Fabry disease symptoms, no family history, and a "sequencing cryptic" $\alpha$-galactosidase a large deletion. Mol Genet Metab. 2011 Nov; 104(3):314-8.

70 Matafora V, Cuccurullo M, Beneduci A, Petrazzuolo O, Simeone A, Anastasio P, et al. Early markers of Fabry disease revealed by proteomics. Mol Biosyst. 2015 Jun;11(6): 1543-51.

71 Bleyer AJ, Zivná M, Kmoch S. Uromodulinassociated kidney disease. Nephron Clin Pract. 2011;118(1):c31-6.

72 Rampoldi L, Scolari F, Amoroso A, Ghiggeri $\mathrm{G}$, Devuyst $\mathrm{O}$. The rediscovery of uromodulin (Tamm-Horsfall protein): from tubulointerstitial nephropathy to chronic kidney disease. Kidney Int. 2011 Aug;80(4):338-47.

73 Ries M, Bettis KE, Choyke P, Kopp JB, Austin HA 3rd, Brady RO, et al. Parapelvic kidney cysts: a distinguishing feature with high prevalence in Fabry disease. Kidney Int. 2004 Sep; 66(3):978-82.

74 Glass RB, Astrin KH, Norton KI, Parsons R, Eng CM, Banikazemi M, et al. Fabry disease: renal sonographic and magnetic resonance imaging findings in affected males and carrier females with the classic and cardiac variant phenotypes. J Comput Assist Tomogr. 2004 Mar-Apr;28(2):158-68.

75 Sayer JA, Haslam P, Brennan P. Parapelvic cysts leading to a diagnosis of Fabry disease. Kidney Int. 2008 Nov;74(10):1366.

76 Pisani A, Daniele A, Di Domenico C, Nigro E, Salvatore F, Riccio E. Late diagnosis of Fabry disease caused by a de novo mutation in a patient with end stage renal disease. BMC Res Notes. 2015 Nov;8(1):711. 
77 Pisani A, Riccio E, Cianciaruso B, Imbriaco M. Simultaneous multicystic kidney and Anderson-Fabry disease: 2 separate entities or same side of the coin. J Nephrol. 2011 NovDec;24(6):806-8.

78 Keyl MJ, Bell RD, Parry WL. Summary of renal lymphatic studies. J Urol. 1973 Mar; 109(3):325-9.
79 Chatterjee S, Shi WY, Wilson P, Mazumdar A. Role of lactosylceramide and MAP kinase in the proliferation of proximal tubular cells in human polycystic kidney disease. J Lipid Res. 1996 Jun;37(6):133444.

80 Deshmukh GD, Radin NS, Gattone VH 2nd, Shayman JA. Abnormalities of glycosphingo- lipid, sulfatide, and ceramide in the polycystic (cpk/cpk) mouse. J Lipid Res. 1994 Sep;35(9): 1611-8.

81 Janich P, Corbeil D. GM1 and GM3 gangliosides highlight distinct lipid microdomains within the apical domain of epithelial cells. FEBS Lett. 2007 May;581(9):1783- 